This discrepancy in the effective inhibitory concentrations of thiourea and thiouracil in these two systems suggested that there might not be any true peroxidase in thyroid and that peroxidase activity could probably be accounted for entirely by hæmoglobin. The peroxidase activity of horse thyroid was in any event small, having an average purpurogallin number (calculated for the water-extractable enzyme) of $6 \times 10^{-3}$. Moreover, the peroxidase activity of dilute hrmoglobin solutions was found to be inhibited to approximately the same extent as the aqueous thyroid extracts by boiling and by thiourea and thiouracil.

The hæmoglobin content of a thyroid extract was determined by the benzidine method as described by Ashby and Chan ${ }^{13}$, and of horse blood diluted to give a solution of the same hæmoglobin content. The peroxidase activity of both diluted blood and of the thyroid extract was determined. In the case of the thyroid extract, the catalase content was first determined by the method of Bancroft and Elliott? and extra hydrogen peroxide added so that the same optimal concentration of hydrogen peroxide was available for peroxidase activity for both diluted blood and thyroid extract. The purpurogallin formed was identical in both cases, showing that the peroxidase activity of the thyroid extract (purpurogallin number of $5.8 \times 10^{-3}$ ) can be accounted for completely by its hæmoglobin content. It must be remembered, however, that in the above experiments an aqueous filtrate of thyroid was used. Bancroft and Elliott found that not all the peroxidase of animal tissues is extractable with water and used a glycerol suspension of the tissue for determining peroxidase activity.

To substantiate the above findings, the total peroxidase activity, using Bancroft and Elliott's glycerol extraction procedure, of horse thyroid, perfused with Ringer through the thyroid artery in an isolated neck preparation until almost blood free, was compared with that of the unperfused thyroid from the same horse. The total peroxidase activity was decreased considerably by perfusion, the perfused thyroid having an almost negligible activity, with a purpurogallin number of $1.0 \times 10^{-4}$. The peroxidase activity of completely blood-free dog thyroids, pooled from twelve dogs previously bled from the heart, was also found to be small, with a purpurogallin number of $4.1 \times 10^{-4}$.

It would appear from these results that the thyroid probably contains no true peroxidase, and that inhibition of the synthesis of thyroxine in the thyroid produced by various goitrogenic agents, including thiourea and thiouracil, cannot be accounted for by inhibition of peroxidase activity. For this reason it is doubtful whether xanthine oxidase participates in thyroxine formation. Moreover, horse thyroid was found to contain none of this enzyme. Bernheim and Bernheim ${ }^{14}$ have shown that phenyl thiocarbamide inhibits tyrosinase activity. Using the purpurogallin method of Keilin and Mann ${ }^{15}$, polyphenolase of potato was found to be inhibited to a considerable extent by thiourea, potassium thiocyanate and sodium fluoride, but aqueous thyroid extracts were found to contain none or negligible amounts of this enzyme.

Experiments are in progress on the effect of thiourea, thiouracil and other goitrogenic agents on the cytochrome oxidase system. Although Mann and Keilin ${ }^{16}$ have shown that sulphonamides do not inhibit cytochrome oxidase activity, it is conceivable that the total concentration of cytochrome oxidase or cytochrome $c$ in the thyroid might be diminished by sulphonamides or thiouracil.

Wellcome Physiological Research Laboratories, G. E. GLOCK. Beckenham, Kent. Aug. 23.

${ }^{1}$ Schachner, H., Franklin, A. L., and Chaikoff, I. L., J. Biol. Chem., 151,191 (1943)

2 Dempsey, E. W.; Endocrinology, 34, 27 (1944).

3 Lipmann, F., J."Biol. Chem., 139, 977 (1941).

Keilin, D., and Mann, T., Proc. Roy. Soc., B, 122, 119 (1937).

"Westerfeld, W. W., and Lowe, C., J. Biol. Chem., 145, 463 (1942). "Keston, A. S., J.'Biol. Chem., 153, 335 (1944).

7 Bancroft, G., and Elliott, K. A. C., Biochem. J., 23, 1911 (1934), S Huszak, Biochem. Z., 312, 330 (1942).

- Altchul, A. M., Abrams, R., and Hogness, T. R., J. Biol. Chem., 136, $777(1940)$.

10 Willstäter, R., and Stoll, A., Ann. chim., 416, 21 (1918).

"1 Elliott, K. A. C., and Keilin, D., Proc. Roy. Soc., B, 114, 210 (1934). ${ }_{13}$ Elliott, K. A. C., Biochem. J., 26,10 (1932).

${ }^{13}$ Ashby, W., and Chan, D. V., J. Biol. Chem., 151, 515 (1943)

"Bernheim,'F., and Bernheim, M. L. C., J. Biol. Chem., 142, 213 Keilin).

${ }_{10}^{18}$ Keilin, D., and Mann, T., Proc. Roy. Soc., B, 125 (1938).

\section{Mepacrine Derivatives in Urine}

IN collaboration with the Army Malaria Research Unit, we have developed a technique for the quantita. tive separation by chromatographic means of mepacrine from urine and from blood. The separation is effected on alumina and is made visible by the intense fluorescence emitted by acridine derivatives in ultraviolet light. In certain (but not all) specimens of urine from some groups of malarial patients receiving therapeutic courses of mepacrine we have observed that a yellow fluorescent band, not that of mepacrine, can be developed on the chromatogram. This band is not observed on chromatograms of normal urines from patients who have not been dosed with mepacrine. Further, a sample of urine to which an authen. tic specimen of pure 2-hydroxy-6-chloro-9-aminoacridine had been added gave a chromatogram exhibiting a yellow band identical with that obtained from the urines referred to above. The two bands, the one obtained from malarial urine and the other produced from a urine to which the amino-compound mentioned had been added, exhibited exactly similar behaviour on the alumina columns. Thus neither band could be eluted using methyl or ethyl alcohol, ether, benzene, chloroform, acetone, amyl alcohol, pyridine or even glacial acetic acid, whereas both bands were eluted by $N$ hydrochloric acid.

A solution of the new acridine derivative was obtained by extruding the chromatogram developed from urine and extracting the band required with $N$ hydrochloric acid. The solution showed the very characteristic change in fluorescent colour from yellow in acid solution to deep orange in alkali at $p \mathrm{H} 10 \cdot 5$, which is characteristic of 2-hydroxy-6chloro-9-amino-acridine. On mixing the solution obtained from the extracted chromatogram with a solution of the authentic hydroxy-amino-compound, it was found impossible to separate the two components chromatographically.

We think it possible that the fraction $C$ isolated from the urine of dogs dosed with mepacrine by Scudi and Jelinck ${ }^{1}$, but not identified by them, may be the 2-hydroxy-6-chloro-9-amino-acridine mentioned above.

Dyson Perrin Laboratory, D. LL. HaMmICK. D. Firth. 